\title{
FOUR CASES of IMMUNO-TRANSFUSION with remarks on the Method
}

\author{
BY \\ E. I. LLOYD, M.B., B.Ch., F.R.C.S., \\ AND \\ B. E. SCHLESINGER, M.B., B.Ch., M.R.C.P. \\ (From the Hospital for Sick Children, Great Ormond Street.)
}

Immuno-transfusion is a comparatively recent extension of treatment by blood transfusion and the following case seems worth recording as an example of recovery from a desperate illness after other methods had apparently failed.

\section{Case I. (vide chart).}

A boy of two years, suffering from a left-sided pneumococcal empyema, was admitted on September 27th, 1924, to Dr. Thursfield's Ward in the Hospital for Sick Children, Great Ormond Street. Two months previously he had developed whooping cough which was followed by broncho-pneumonia, and he became suddenly worse on the day before admission.

$\mathrm{Rib}$ resection with drainage was performed on October 15th, but the child's temperature and pulse remained high, and his condition was still critical. Two weeks later the left testis became tender and swollen; this was thought to be a metastatic infection and confirmation was obtained on November 5th when pneumococci were grown from his blood. The urine was normal. A course of vaccine and serum treatment was tried but failed, and on November 13th, immuno-transfusion was carried out by the method recommended by Colebrook and Storer. (1) A pneumococcal vaccine was prepared from the patient's blood culture and a dose of 1,000 million was injected into his father; five hours later $350 \mathrm{ccs}$. of the father's blood were removed, defibrinated and injected into the child's median basilic vein. His temperature and pulse fell immediately and by the next morning he was much better.

Except for a rise of temperature on the third day, when he developed a fresh orchitis on the same side, the improvement was maintained for a week, and on November $21 \mathrm{st}$ his blood culture was sterile. On November 24th there was a further pulmonary involvement on the opposite side and a small accumulation of pneumococcal pus in the corresponding pleural cavity was removed by aspiration. On this occasion the child's own defences proved adequate to overcome the infection; his temperature and pulse were normal in five days and he was well enough to be discharged from hospital on December 12th, 1924. Since that time he has been well and was seen six months later (June, 1925) when the left lung had expanded, the wound was still healed and his general condition, except for a little residual bronchitis, remained excellent.

It will be seen from the chart that the prolonged administration of polyvalent pneumococcal serum and stock sensitized vaccine, as well as two doses of autogenous vaccine (November 11 th and 12th) were without appreciable effect and that the improvement dates from the immunotransfusion given on November 13th. 
It is difficult to be certain what were the principal factors in the child's recovery. Some, no doubt, will attribute it to the vaccine, serum or fixation abscess, but it is our wwn definite impression that immuno-transfusion was the turning point in the illness, and we think that this is substantiated by the chart.

One of us has treated three other cases by this method and all three have died. Nevertheless septicæmia is such a fatal condition that one success is not entirely discounted by three failures. Brief details of the three latter are given below.

\section{Case II.}

A girl of seven years suffering from pericarditis, and with staphylococcus aureus in the blond following an osteomyelitis of the upper thircl of the femur. One immuno-transfusion was given.

\section{Case III.}

A boy of eight years with a very similar bone infection and streptococci in the blood. He had been treated with antistreptococcal serum and two doses of perchloride of mercury (one-thirty-second and one-fortieth of grain) intravenously before immuno-transfusion was carried out.

Case IV.

A boy of two years with a streptococcal blood infection following a post-auricular abscess. Iisease of both midclle ears and thrombosis in one lateral sinus were demonstrated post-mortem. This child was given two immuno-transfusions.

It is noteworthy that recovery occurred in the pneumococcal infection, and such cases do not appear to have been treated by this method.

\section{The Origin, Progress, and Criticisms of the Method.}

Septicæmia has been frequently treated by simple blood transfusion, but the results have been disappointing: Sir Almroth Wright ${ }^{(2)}$ suggests that it may do actual harm by providing additional and better culture medium. The next step(3) (4) was the injection of blood from patients who had recently recovered from the same infection (e.g., typhoid fever and pneumonia) and whose blood was presumed to have a specific power against one particular organism. The artificial production of this immunity in the donor was attempted by $\operatorname{Hooker}^{(5)(6)}$ in 1913 . Wright ${ }^{(7)}$ elaborated the method and carried out a long series of laboratory experiments. The main bacteriological evidence and clinical results of this work are given in two papers by Colebrook and Storer ${ }^{(1)}$ in the Lancet for 1923 . The method briefly stated is as follows :-

The donor's blood is tested against that of the patient, and a dose of one thousand million stock staphylococcal or one hundred million typhoid vaccine is injected subcutaneously into the donor. Four to five hours later $500 \mathrm{ccs}$. of blood (for an adult patient) is removed from the donor, defibrinated and injected into the patient intravenously. The technique of this simple operation is clearly described by Colebrook and Storer (loc. cit.). It is important to observe the stated dose and time in order to avoid the possibility of transfusing the blood during the negative phase. 
In advancing septicamias the bactericidal reaction of the patient's blood has been overwhelmed. The mass immunisation response, previously induced in a healthy donor, is transferred to the patient by the immune blood, and reinforces his hæmo-bactericidal power. Furthermore, the addition of many fresh red and white cells must be beneficial.

Much has been written on the relative advantages of using whole and citrated blood in transfusions. Although unmodified whole blood is the ideal, its use has been restricted by technical difficulties. Citrated blood is free from these, but is unsatisfactory inasmuch as the red blood cells are made more fragile, and severe reactions are produced in from 40 to $50 \%$ of cases according to some observers. (10)(11) In addition, it has been shown ${ }^{(12)}$ that the bactericidal efficiency of the blood for staphylococcus and streptococcus is diminished by decalcifying agents. Defibrination overcomes all these difficulties and only entails a loss of 25 to $30 \%$ of the white blood cells.

The optimum time for removing the blood after injecting the vaccine lats been experimentally worked out by Wright and his colleagues, (7) who find that the maximum bactericidal response is produced in from four to six hours. Wright ${ }^{(2)}$ recommends suitable stock rather than autogenous vaccine for the donor. Undoubtedly there is a non-specific factor in the reaction. In the four cases described, however, autogenous vaccine was used. It is difficult to foretell which cases will respond to immuno-transfusion, but an unevacuated nidus of infection precludes any hope of success from the method. Passive immunity is no weapon against an undrained abscess.

Summary and Conclusion.

1. Four cases of proved septicæmia treated by immuno-transfusion with one recovery and three deaths are described.

2. The success occurred in a pneumococcal septicæmia consequent upon empyema and seems attributable to the transfusion.

3. All four cases had previously undergone surgical operations.

4. Immuno-transfusion, though by no means a certain cure for septicæmia, offers a hopeful line of treatment in some cases.

We are indebted to Dr. J. H. Thursfield, Mr. G. E. Waugh, Mr. H. A. T. Fairbank and Mr. O. L. Addison for permission to refer to their cases, and desire to thank Dr. Thursfield in addition for his help and criticism in the preparation of this paper.

\section{REFERENCES.}

1. Colebrook, L.., and Storer, E. J. : Lancet, 1923, ii., 1341, 1394.

2. Wright, Sir Almroth: Lancet, 1919, i., 489.

3. Mcclure, R. D., and Dunn, (.. R.: Bull. John. Hop. Hosp., 1917, xxviii., 99.

4. Ross, C. W., and Hund, E. J.: Jour. Amer. Med. Issoc., 1918, lxxi., 1992.

5. Hooker, R. S. : Arch. Int. Med., 1914, xiii., 71.

$6 . \quad$ Annals of Surgery, 1917, 1xvi., 513.

7. Wright, Sir Almroth, Colebrook, L., and Storer, E. J. : Lancet, 1923, i., 365, 417, 473

8. Moss, W. L. : Jour. Amer. Med. Assoc., 1917, lxviii., 1905.

9. Libman, E., and Ottenberg, R. : Trans. Coll. Phys. Philad., 1917, xxxix., 266.

10. Drinker, C. K., and Brittingham, H. H. : 1rch. Int. Mcd., 1919, xxiii., 133.

11. Stetson, M. D.: Amer. Jour. Med. Sci., 1924, N.S., clxviii, 534.

12. Colebrook, I..: Brit. Jour. Exp. Path., 1924, v., 47.

FURTHER CASES TREATEI) BY IMMUNO-IRANSFUSION.

Heyd, G. (i. (quoted by Robertson, W. F.) : Lancet, 1918, i., 761.

little, G. F.: Jour. Amer. Med. Assoc., 1920, 1xxiv., 734.

Fry, H. J. B. : B.M.J., 1920, i., 290.

Wordley, E.: Lancet, 1924, ii., 219. 
Chart of Case I.

(Lower line temperature, upper line pulse.)
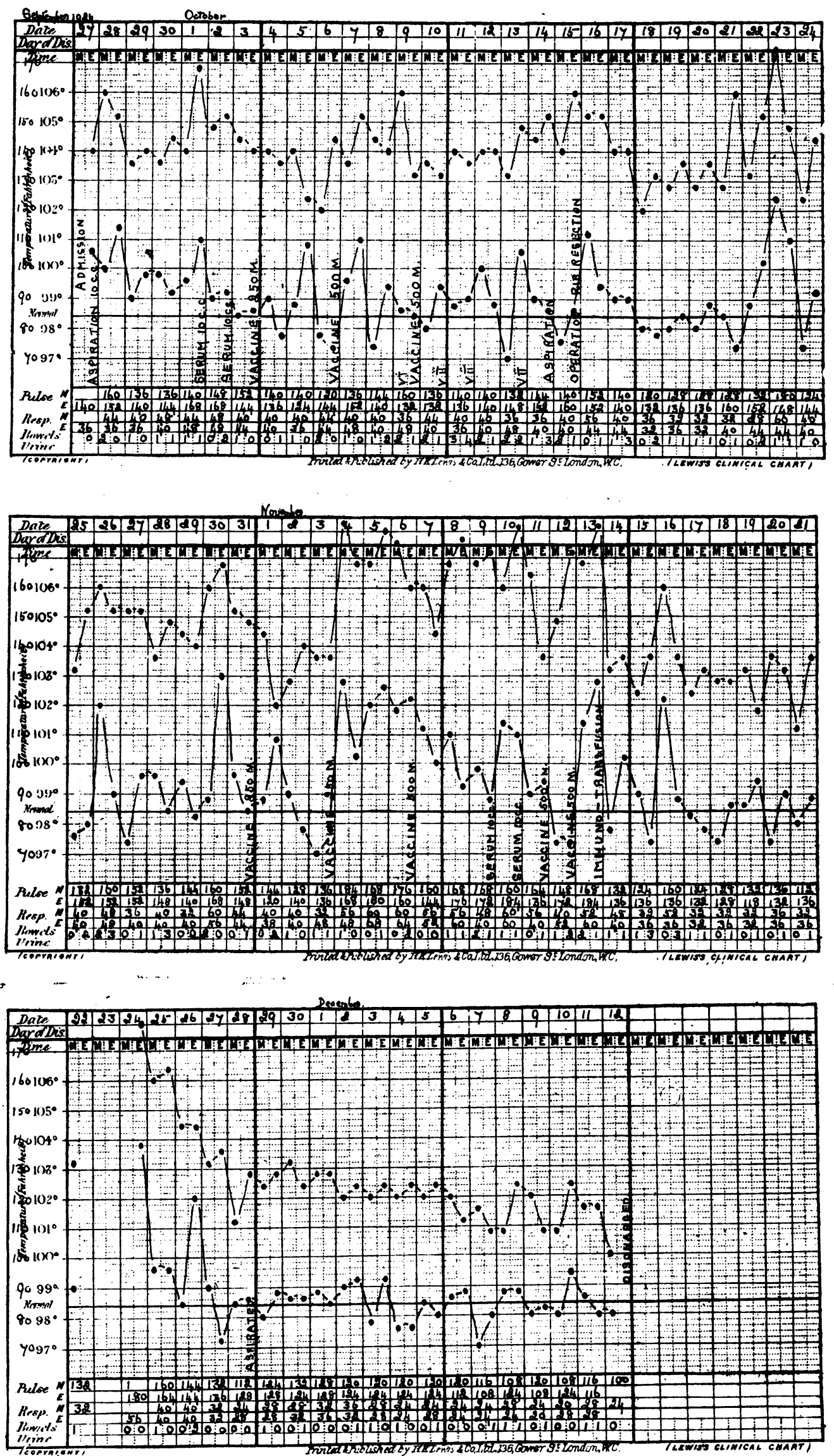

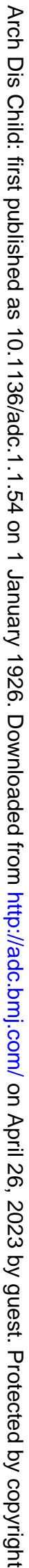

NOTES

1. Polyvalent antistreptococcal serum (Burroughes and Wellcome) was used.

2. The vaccine was stock " sensitized" pneumococcal except that given on Nor: 11th and 12th, which was autogeno:1s.

3 Immuno-transfusion was carried ant on Nov. 13th. 